\title{
Applying Importance Measures to Risk Analysis in Engineering Project Using a Risk Network Model
}

\author{
Chao Fang, Franck Marle, and Min Xie, Fellow, IEEE
}

\begin{abstract}
Risk analysis and prioritization is a key process in project risk management. Its outcomes serve as input of the risk response planning process where decisions are made. Complexity of projects is characterized by the emergence of phenomena that are difficult to detect and to manage using classical methods. It may disturb risk assessment, on which priorities are further established. This paper aims at using importance measure techniques in the complex project risk management field. This involves modeling the complex project risk network and providing complementary analysis results based on risk importance measures accounting for risk interactions. These new project risk indicators allowthe managerfora morecomprehensive understanding ofthe risks. An application to a complex engineering project is provided to illustrate this approach to assess both risks and risk interactions, in order to establish priorities for further decision-making.
\end{abstract}

Index Terms - Complexity, risk interaction, risk analysis, importance measures, project management

\section{INTRODUCTION}

Risk management is indispensable for the successful realization of projects. The Project Management Institute defines a project risk as "an uncertain event or condition whose occurrence affects at least one of the project objectives, e.g., scope, schedule, cost and quality"[1]. The classical steps of Project Risk Management (PRM) involve: risk identification, risk analysis, risk response planning, risk monitoring \& control and lessons learned. A common and critical issue in the PRM process is to assess and determine the relative priority of various risks. As projects are subject to more uncertainties and tight budget constraints, it is necessary for the manager to identify the most important risks to take care of, because no project can afford to manage and control all the potential risks. In this regard, risk analysis is required to prioritize risks and then the manager can allocate resources to mitigate the most

This work was supported in part by the NSFC Grant No. 71301123, 71231007, by SRF for ROCS, SEM and "the Fundamental Research Funds for the Central Universities".

*C.Fang is with the School of Economics andManagement,WuhanUniversity,Wuhan 430072, China (e-mail: chao.fang@whu.edu.cn).

F. Marle is with the Laboratoire Genie Industriel, Ecole Centrale Paris, 92290Chatenay-Malabry, France (e-mail: franck.marle@ecp.fr).

M. Xie is with the Department of Systems Engineering and EngineeringManagement, City University of Hong Kong, Hong Kong, China (e-mail:minxie@cityu.edu.hk). critical ones.

Risks are generally assessed with respect to their probability (of occurrence) and impact (of their materialization). Risk rating or criticality is used as an aggregate measure of risk importance, and it is often defined as the product of risk probability and impact scores [1-3]. A widely praised and adopted as simple, effective tool for risk prioritization in PRM practice and other contexts is the 'risk matrix' or 'probability-impact grid' (PIG) [4,5].However, some researchers highlight the weakness related to the fact that interdependencies among risks are not properly considered in PRM just using the risk matrix or the PIG approach [6-8]. For example, Salado and Nilchiani have discussed the importance of modeling risk dependencies and hence the uncertainty propagation $[9,10]$.

Indeed, projects are facing a growing complexity due to the involvement of numerous, diverse and strongly interrelated elements [11-14]. This leads to an increasing number of interdependent risks, which must be taken into account in order to be able to put properly priorities to these risks. Some research have discussed how to model and understand the complexity in network structures, e.g., in [15-19]. A modeling and analysis process of the risk network will be used in this paper based on previous works[20].

Complexity appears to be one of the main reasons of the unpredictability of projects, particularly in terms of problems and failures. There is a high number and great diversity of interdependent elements to manage, with also a lot of and diverse parameters that characterize them. The amount and diversity of these interactions are huge that projects rapidly become unmanageable due to the sole use of classical project management tools and methods like the mentioned risk matrix or the PIG approach. Both the complexity of the evolving environment and the internal complexity of the project justify the need for a new approach. For instance, some events may occur and eventually propagate throughout the project, which is likely to reduce the project performance if this emergent behavior is not properly anticipated and controlled[21, 22].

The approach using importance measures (IMs) was first introduced by Birnhaum [23], and a series of IMs have been proposed afterwards [24-27]. They all aim at quantifying the contribution of individual components to the system performance and have been developed in different fields, like reliability, risk, availability, throughout [28-32]. Besides, some 
other risk measures like mean-riskmeasure have been widely applied in systems engineering. For example, Choi and co-authors conductedmean variance analysis on inventory management and supply chain management[33-35].In this research, we propose to measure the importance of risk with regard to its contribution to the global project risk exposure.The originality of this paper is tailoring and application of some importance measures to refined project risk assessments, taking into account risk interactions. Namely, the measure and ranking of risks in terms of their importance in the risk network may differ from the classical project risk analysis results. The importance of risk interactions can also be measured and prioritized with respect to their role in the risk network. The approach can thus provide more comprehensive understanding of project risks and perhaps novel insights for decision-making. This work proposes a refined priority of risks and a complementary priority analysis of risk interactions. It is regarded as an initial step to develop dependency-driven risk assessment methods.

Risk assessment or estimation involves using qualitative or quantitative approaches. In the context of projects, no previous experience can be reused as is, and the number of similar projects is not high enough to get significant statistics based on the past. The aim of this work is to give rankings, order of magnitudes where gaps between different risks are significant compared to the error made in estimates. The important thing is how data are transformed in order to analyze relatively risk importance, independently of the reliability of initial risk estimate.

The remainder of the paper is organized as follows. Section 2 introduces a project risk network to model the complexity of risk interdependencies. Section 3 proposes some importance measures to project risks considering their interactions with respect to their contribution to the overall project risk exposure. Section 4 illustrates how the proposed approach is tested on a real large engineering project in the construction industry. Finally, some conclusions are drawn and perspectives are discussed in Section 5.

\section{A RISK NETWORK-BASED MODEL}

The aim of this work is to combine importance measures applied on refined risk assessments, considering risk interactions. Based on classical project risk analysis methods, a risk network model is built to capture the project risks and the propagation behavior through their interactions.

\section{A. Classical Project Risk Assessment Techniques}

Risk criticality is used as an aggregate measure of risk importance, and is often defined as the product of risk probability and impact, or severity [1-3].

Qualitative scales are often used to express project risk probability with 5 to 10 levels (e.g., very rare, rare, unlikely, likely, etc.), which typically correspond to non-linear probability measures (e.g., $10^{-4}, 10^{-3}, 10^{-2}, 10^{-1}$, etc.) $[6,36]$. To avoid some fundamental flaws in calculation according to [37], the qualitative scales need to be converted to quantitative measures of risk probability[20]. Logarithmic scales have been used by statisticians for many decades [38]. They allow us todistribute probabilities unevenly. In practice, they devote more space to small values, imposing a compressed, logarithmic mapping. For our calculations, based on this principle, we use the following mappingEquation:

$$
P=\alpha * 10^{-\beta / s}
$$

where $P$ is the quantitative probability measure, $s$ indicates the qualitative scale value, with parameters $\alpha>0, \beta>0$. Risk impact is assessed by classical PRM methods, based upon a mix of previous experience and expert judgment [1,39].

In practice, if risks are analyzed individually (i.e., without considering the interrelationship among risks), the classical risk criticality indicator can be used to measure the importance of a risk:

$$
\text { Criticality }_{i}=P_{i} * I_{i}
$$

where $P_{i}$ and $I_{i}$ indicate the estimated probability and impact of Risk $i$.

When considering a project with $N$ risks, a potential objective function $O$ of risk management, i.e., the project risk exposure, can be defined as [40, 41]:

$$
O=\sum_{i=1}^{n} \text { Criticality }_{i}=\sum_{i=1}^{n} P_{i} * I_{i}
$$

The next section shows how the consideration of risk interactions in our approach may change values of parameters in Eq. (3).

\section{B. Modeling and Analyzing the Project Risk Network}

A risk network model is used to capture the project risks and their interactions, and to reassess their values in terms of refined probability and refined criticality. This work is an initial attempt to incorporate risk dependency in risk analysis for non-probabilistic risk assessment methods since only materialization dependency has been incorporated. Such network representation models the individual risks and their interactions which convey the risk propagation behavior, i.e., the occurrence of one risk triggering another risk in the network. Simulation technique is used to run the model and observe the occurrence of risks. In what follows, the risk network model is briefly described. Readers may refer to[20] for more details.

First, the network is built. Risk interaction is considered as the existence of a possible precedence relationship between two risks [42]. Multiple experts are engaged for this modeling task, after being made aware of the possible confusion between direct and indirect interactions among risks, and being asked to concentrate on direct dependencies. In the context of project risk management, there is generally not enough experience on identification and assessment of risk interactions. This is why expertise is the chosen way in this study to model them. The interrelations between project objects, such as tasks, actors and product components, can facilitate the identification of interrelations between the risks related to these objects. 


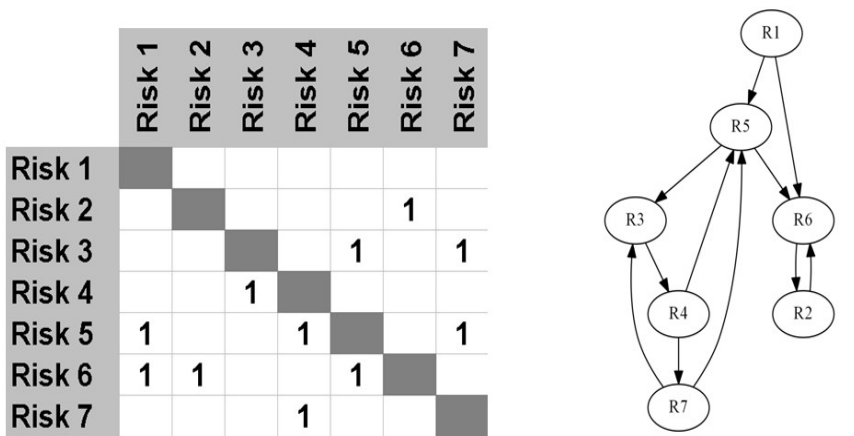

Fig. 1. Matrix-based representation of project risk network (adapted from [20]).

Generally, an indirect cause-effect dependency involves modeling at least one additional intermediary node and additional edges between the cause and the effect. This means that the initial risk list may be enriched thanks to risk interaction identification.

We define the Risk-Risk Matrix (RR), which is a square matrix called MDM (Multi-Domain Matrix) in the Dependency and Structure Modeling (DSM) approach $[43,44]$ as follows:

$$
\left\{\begin{array}{rr}
R R_{i j}=T P_{i j} \text { if there is a cause }- \text { effect } & \text { relationship from risk } j \text { to } i \\
R R_{i j}=0 & \text { otherwise }
\end{array}\right.
$$

where the transition probability $T P_{i j}$ is defined as the probability that the occurrence of the cause risk $j$ triggers the occurrence of the effect risk $i$.

There is then an important distinction between the spontaneous probability (that a risk is caused by external events or risks which are outside the scope of the model) and the transition probability (that a risk is triggered by another risk within the model). For the example in Fig. 1, Risk 1 occurs only in accordance with its spontaneous probability; and Risk 3 may arise from both its spontaneous probability and the transition probabilities from Risk 5 and Risk 7.

Finally, the weighted network is analyzed through simulation. A large number of iterations are conducted for each scenario of simulation, where the occurrence of every risk during the run is recorded. The observed probability or frequency of each risk in the simulation may change or not. This new value due to the risk propagation behavior is called $P^{\prime}$. Hence, the output of global risk exposure becomes:

$$
O^{\prime}=\sum_{i=1}^{n} P_{i}^{\prime} * I_{i}
$$

\section{TAILORING IMPORTANCE MEASURES TO THE PROJECT RISK NETWORK}

This section introduces an approach to combining the refined risk assessment (considering risk network instead of individual risks) and the importance measure techniques. We tailor several risk importance measures to the context of project management. The value of the proposed risk IMs can be obtained by the introduced risk network model using simulation techniques. Various IMs can provide project manager with diverse insights on risks and risk interactions with respect to risk management.

\section{A. Risk Importance Measures}

Several risk importance measures are proposed based on the refined risk values using the risk network model:

Risk Achievement Value:

$$
R A V_{i}=O^{\prime}\left(R_{i}=1\right)-O(\text { base })
$$

$$
\begin{aligned}
& \text { Risk Reduction Value: } \\
& \quad R R V_{i}=O(\text { base })-O^{\prime}\left(R_{i}=0\right)
\end{aligned}
$$

$$
\begin{aligned}
& \text { Marginal Risk Value: } \\
& \qquad \operatorname{MRV}_{i}=O^{\prime}\left(R_{i}=1\right)-O^{\prime}\left(R_{i}=0\right)
\end{aligned}
$$

Here $O$ is the defined objective function for PRM, namely the overall risk exposure; $O$ (base) is the estimated value without carrying out any risk management activities; $O^{\prime}\left(R_{i}=\right.$ 1) indicates the achieved risk exposure under the condition that the spontaneous probability of Risk $i$ is set to 1 while the other risks remain the original status (i.e., with the estimated spontaneous probability to occur); $O^{\prime}\left(R_{i}=0\right)$ indicates the value of $O$ given that the spontaneous probability of Risk $i$ is set to 0 (others remain).

The $R A V_{i}$ specifies the maximum potential increase from the estimated global risk exposure if Risk $i$ is out of control and determined to occur with $100 \%$ probability. The $R R V_{i}$ represents the maximum potential decrease of the global risk exposure by investing to directly mitigate Risk $i$. The $M R V_{i}$ is irrelevant to the estimated value of the spontaneousprobability of $R_{i}$. It thus reflects the importance of $R_{i}$ with respect to its structural position in the risk network. In other words, it denotes the range of influence of $R_{i}$ on the overall objective function and follows:

$$
M R V_{i}=R A V_{i}+R R V_{i}
$$

We divide these measures by $O$ (base) to express their fractional contribution to the overall risk exposure. The ratios are also easier to use as IMs for risk ranking. The formulas are as follows:

$$
\begin{aligned}
& \text { Risk Achievement Importance: } \\
& R A I_{i}=\frac{\left.O^{\prime}\left(R_{i}=1\right)-O \text { (base }\right)}{O(\text { base })}
\end{aligned}
$$

Risk Reduction Importance:

$$
R R I_{i}=\frac{O(\text { base })-O^{\prime}\left(R_{i}=0\right)}{O(\text { base })}
$$

Marginal Risk Importance:

$$
M R I_{i}=\frac{O^{\prime}\left(R_{i}=1\right)-O^{\prime}\left(R_{i}=0\right)}{O \text { (base })}
$$

\section{B. Risk Interactions Importance Measures}

Besides individual risks, the importance of risk interactions can also be measured in terms of its influence on the global risk 


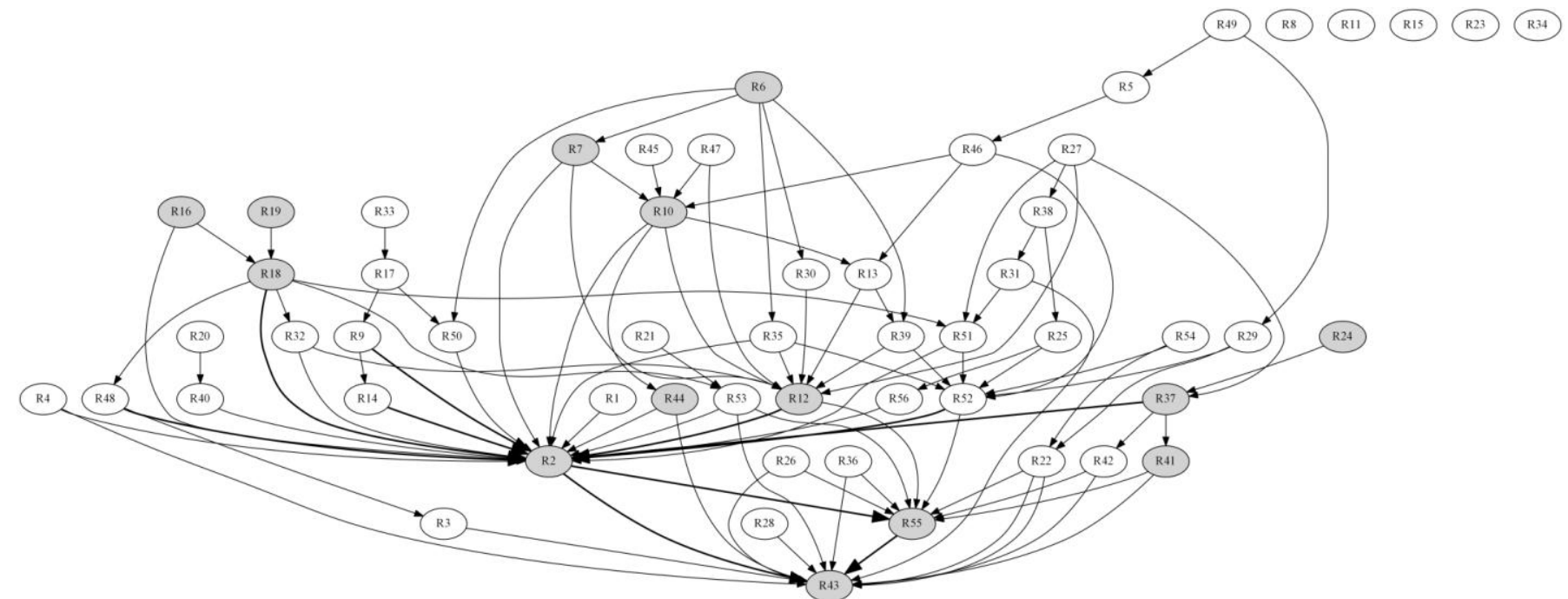

Fig. 2. Tramway engineering project risk network (with highlighted important risks and interactions)

exposure:

Risk Interaction Achievement Importance:

$$
R A I_{i \rightarrow j}^{I}=\frac{O^{\prime}\left(e_{i \rightarrow j}=1\right)-O(\text { base })}{O \text { (base })}
$$

Risk Interaction Reduction Importance :

$$
R R I_{i \rightarrow j}^{I}=\frac{O(\text { base })-O^{\prime}\left(e_{i \rightarrow j}=0\right)}{O(\text { base })}
$$

$$
\begin{aligned}
& \text { Marginal Risk Interaction Importance: } \\
& \qquad M R I_{i \rightarrow j}^{I}=\frac{O^{\prime}\left(e_{i \rightarrow j}=1\right)-O^{\prime}\left(e_{i \rightarrow j}=0\right)}{O \text { (base })}
\end{aligned}
$$

In a similar sense, $e_{i \rightarrow j}=1$ and $e_{i \rightarrow j}=0$ translate into respectively enhancing the corresponding edge of risk interaction from $R_{i}$ to $R_{j}$ in the network (set its transition probability $T P_{j i}$ to 1 ) or blocking it (set the transition probability $T P_{j i}$ to 0 ). The $R A I^{I}, R R I^{I}$, and $M R I^{I}$ for risk interaction edges have similar implications to the counterpart measures for risk nodes in the network.

\section{APPLICATION TO A REAL ENGINEERING PROJECT}

In this Section, we illustrate the application of the proposed approach to a real large engineering project, aimed at building the infrastructure and associated systems of the future tramway in a medium-sized city in Europe. The project includes the construction and implementation of tramway, equipment, and civil work, with 10 years duration and hundreds of millions $€$ budget. The leading company is a designer and manufacturer of trains, which recently extended its scope by proposing "turnkey" projects, including not only the trains, but also the complete infrastructure around the trains.

\section{A. Identifying Risks and Building the Risk Network}

A project risk list is provided by the project manager and the expert team, containing 56 identified risks at the main level, with their name, domain information, as shown in Table III in the Appendix. Basic characteristics of risks have been assessed by the project manager and associated experts, including qualitative probability and impact scales, as well as criticality measure (product of probability and impact).

Qualitative scales of probability are then converted into quantitative metrics through Eq. (1), setting parameters $\alpha=5$, $\beta=8$ by experience. We adoptimpact scales that existed in the organization to estimate the impact gravity of project risks. Becauserisk impacts are in essence multi-dimensional (namely in terms of schedule, cost, quality, etc.), hence hard to create comparable quantitative scales, in this case study we only multiply the qualitative scales by a constant for quantification. Besides, the importance measures in terms of ratio are not sensitive to the value scales of impact.

Identification of the risk interdependencies (by the steps described in Section 2.2) allows defining the structure of the project risk network, shown in Fig. 2. The network is comprised of 56 risks and 95 risk interactions, with only 5 isolated risks (R8, R11, R15, R23 and R34). For each risk, experts were asked to provide information about the potential causes and effects (to explore the row and the column in the RR matrix corresponding to the considered risk). In the end, the aggregation of local cause-effect relationship identifications makes it possible to display the global risk network. This enables a final meeting to be organized in which interviewees can propose new nodes and connections in the risk graph.

It is mandatory to assess the strength of risk interactions. To do this, two approaches may be considered. The first one is to evaluate them directly using expert judgment, for instance on a 10-level Likert scale. A second solution is to use pair wise comparisons, for instance using the Analytic Hierarchy Process[45], as previously introduced in [46]. Thanks to the high expertise of interviewees, no AHP-based evaluation was performed in this case, although we would recommend it in most cases.

Furthermore, some bias may be included in the assessment of interactions since it appears that interactions are often conceived in terms of impact and not in terms of precedence. Moreover, this step requires the participation of several experts involved in the project since it necessitates a very wide 


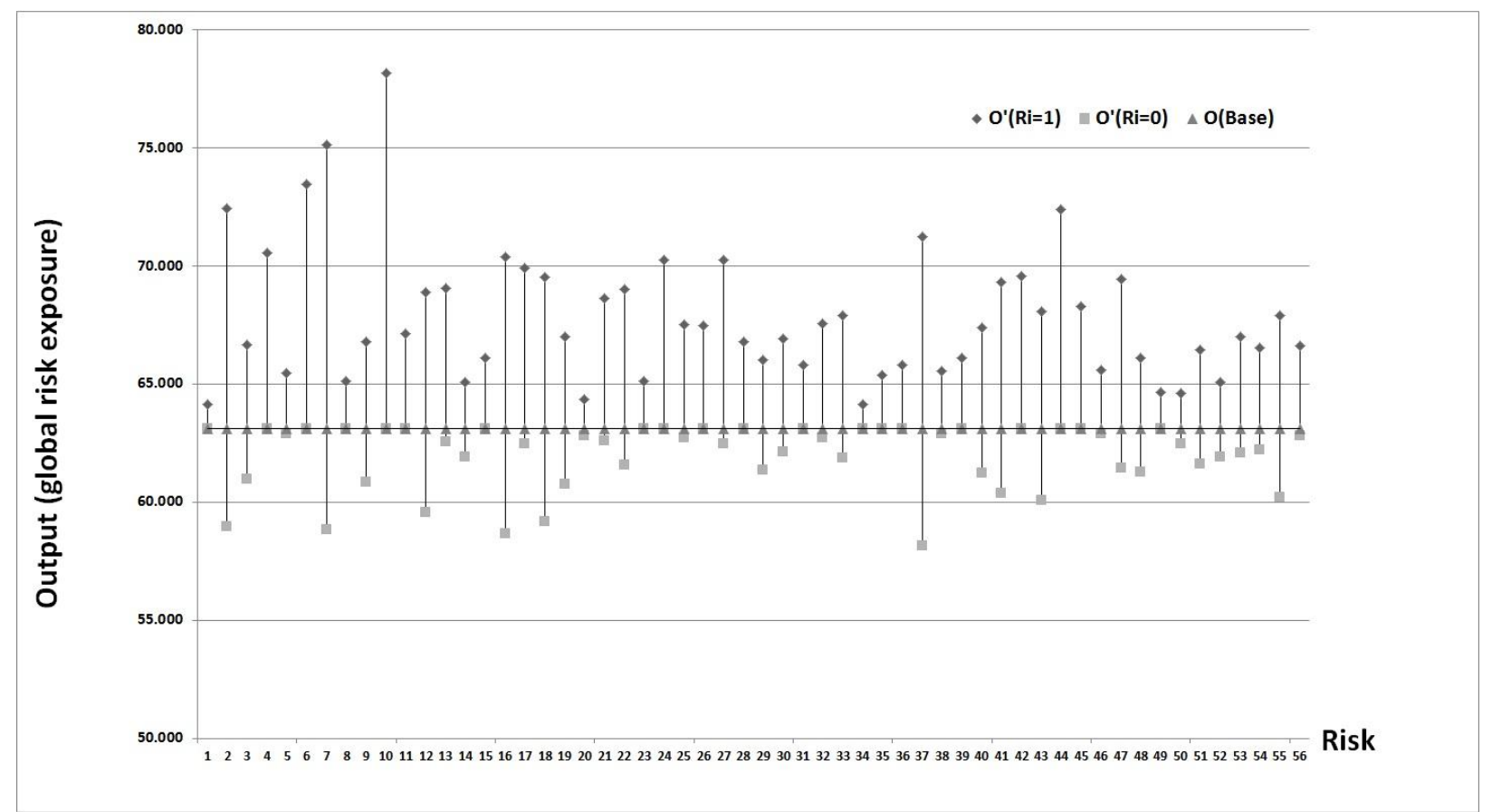

Fig. 3. Illustrating the contribution of each risk on the global risk exposure

overview of the project elements and stakes. Great attention should thus be paid to that point when analyzing the results.

One may wonder when is the most appropriate moment to perform this risk network modelling process and the related analysis. Early modelling enables discussions between people who would not have necessarily been in relation due to the project organization to be facilitated. However, information may be neither available nor reliable at the very beginning of the project. The decision about the analysis schedule is thus a balance between doing it early enough and having reliable enough information. In this case, the project had already been launched with eight risk review meetings before the beginning of the study.

B. Results and Analysis
The relevant values of $\mathrm{O}$ (base), $O^{\prime}\left(R_{i}=1\right)$ and $O^{\prime}\left(R_{i}=\right.$ 0 )for each risk $R_{\mathrm{i}}$ are calculated by simulating the risk network model. In this work, we use the software ARENA ${ }^{\circledR}$ for simulation. The number of simulation iterations are increased gradually from $1000,2000, \ldots$, to 20000 , and the occurrence of each risk during the run is recorded. The results are then found stable after 14000 iterations. We adopted 20000 iterations in this case study forcomputational convenience. The simulation cost is not a limiting factor as the total running time using ARENA on a normal PC is less than 10 minutes. The results shown in Fig. 3 visually illustrate the contribution, namely the varying range of influence, of each risk to the output of global risk exposure.

The values of the proposed risk IMs are then consolidated and compared with the classical risk criticality analysis. We

TABLE I

TOP-TEN RISKS ACCORDING TO VARIOUS IMS

\begin{tabular}{|c|c|c|c|c|c|c|c|c|}
\hline \multirow{3}{*}{ Ranking } & \multirow{2}{*}{\multicolumn{2}{|c|}{ Classical risk criticality measure }} & \multicolumn{6}{|c|}{ Importance Measures of Risks } \\
\hline & & & \multicolumn{2}{|c|}{$R A I$} & \multicolumn{2}{|c|}{$R R I$} & \multicolumn{2}{|c|}{ MRI } \\
\hline & Risk ID & Value & Risk ID & Value & Risk ID & Value & Risk ID & Value \\
\hline 1 & $R 43$ & 3.048 & $R 10$ & 0.238 & $R 37$ & 0.079 & $R 7$ & 0.258 \\
\hline 2 & $R 37$ & 2.667 & $R 7$ & 0.190 & $R 16$ & 0.071 & $R 10$ & 0.238 \\
\hline 3 & $R 55$ & 2.667 & R6 & 0.164 & $R 7$ & 0.068 & $R 2$ & 0.213 \\
\hline 4 & $R 2$ & 2.465 & $R 2$ & 0.147 & $R 2$ & 0.066 & $R 37$ & 0.207 \\
\hline 5 & $R 3$ & 1.905 & $R 44$ & 0.147 & $R 18$ & 0.063 & R16 & 0.186 \\
\hline 6 & $R 40$ & 1.541 & $R 37$ & 0.128 & $R 12$ & 0.056 & R18 & 0.164 \\
\hline 7 & $R 12$ & 1.524 & $R 4$ & 0.118 & $R 43$ & 0.048 & $R 6$ & 0.164 \\
\hline 8 & R18 & 1.524 & R16 & 0.115 & $R 55$ & 0.046 & $R 12$ & 0.148 \\
\hline 9 & $R 29$ & 1.524 & $R 27$ & 0.113 & $R 41$ & 0.044 & $R 44$ & 0.147 \\
\hline 10 & $R 7$ & 1.314 & $R 24$ & 0.113 & $R 19$ & 0.038 & $R 41$ & 0.142 \\
\hline
\end{tabular}


highlight the prioritized top-ten risks according to different indicators in Table I. It is found that the rankings using the proposed risk IMs are quite different from the classical risk analysis results. For example, the most critical risk identified by classical analysis was R43 (Return profit decrease), which is closely related to the financial performance of the project. However, after taking into account the risk propagation behavior, some other risks occupy the pole or premier critical position according to different IMs. Another example is R3 (Vehicle storage in another city), which was regarded important, but has fallen out of the top-ten list according to the proposed IMs. Overall, several of the critical risks identified by classical risk criticality analysis have been confirmed by the proposed IMs, e.g., R37 (Risk of partial rejection of our request for extension of time), R2 (Liquidated damages on intermediate milestone and delay of Progress Payment Threshold), R12 (Operating certificate delay) and R18 (Civil Work delay \& continuity). But in addition, some new risks have been highlighted as key factors by the proposed approach, which are supplementary results and provide the manager with new insights on the risk network.

Specifically, R7 (Traffic signaling, priority at intersections), R10 (Travel Time performance) and R2 (Liquidated damages on intermediate milestone and delay of Progress Payment Threshold) are ranked as the top-three risks with marginal influence on the global risk exposure. R10 has a very high $R A I$ but not identified as important risk in terms of its $R R I$ value. It means that although the decrease of risk exposureis relatively low by carrying out mitigation actions on R10, the potential damage/loss could be significant if R10 happens. Thus, the project manager should not propose preventive actions on R10, but keep on monitoring it during the project progress. On the other hand, R7 and R2 also have high RRI values. Hence, it would be worthy to plan risk mitigation actions on them, although the feasibility of actions should be considered.

Because the edges of risk interactions and the nodes of risks in the network are basically different in nature and may be suitable to adopt different kinds of mitigation actions, from the practical point of view, we separately measure and rank them. In this case study, we only consider the Marginal Risk Interaction Importance $M R I^{I}$ for risk interactions. The top-ten critical risk interactions are listed in Table II. These important interactions together with the identified key risks, i.e., the most important factors that affect the output $O$ of risk exposure, are highlighted in Fig. 2. It is obvious that most of the important risk interactions are related to $\mathrm{R} 2$ (Liquidated damages on intermediate milestone and delay of Progress Payment Threshold). The reasons are not only that R2 itself has high importance, and it also plays a hub role in the risk network (see Fig. 2). Many other risks will directly or indirectly lead to R2; and R2 has intense relationship with R43 (Return profit decrease) and R55 (Available cash flow decrease) which are also critical risks with high consequences. The project manager should pay attention to the key risk interactions and make efforts to mitigate the risk propagation through them, e.g., by enhancing communication between corresponding actors or preparing alternative solutions to share the risks.
TABLE II

TOP-TEN RISK INTERACTIONS ACCORDING TO MRI ${ }^{\mathrm{I}}$

\begin{tabular}{|c|c|c|}
\hline Rank & Risk Interaction ID & $M R I^{I}$ \\
\hline 1 & $R 2->R 43$ & 0.220 \\
\hline 2 & $R 2->R 55$ & 0.212 \\
\hline 3 & $R 55->R 43$ & 0.150 \\
\hline 4 & $R 18->R 2$ & 0.139 \\
\hline 5 & $R 12->R 2$ & 0.129 \\
\hline 6 & $R 52->R 2$ & 0.108 \\
\hline 7 & $R 9->R 2$ & 0.096 \\
\hline 8 & $R 48->R 2$ & 0.093 \\
\hline 9 & $R 14->R 2$ & 0.089 \\
\hline 10 & $R 37->R 2$ & 0.089 \\
\hline
\end{tabular}

\section{Discussion}

The risk list used in this research has been directly provided by the manager and corresponded to the list currently used in the project. The formulation and semantics of risks are themselves an issue, and not only in this case. However, the requirement of the manager was to identify the influence of interdependencies between risks on the behavior of the project. The aim was to analyze the gap with the current representation of this behavior, based on classical project risk management techniques and on the classical assumption of independence. Behind the formulation of the risk, there is always an event corresponding to the dissatisfaction of a stakeholder or of a parameter of the project/product. For instance, R5 "Traction/breaking function" corresponds to the risk of unsatisfying performance of the traction/breaking function for the client. Similarly, the following risks mean "unsatisfying travel time performance", "unsatisfying harmonics level", even if the word unsatisfying was not present. This imperfect formulation of risks is a potential source of misinterpretation, not only on risks but also on risk interactions. This is why the work of risk interaction identification and assessment had to be made with several experts and several meetings to be sure to avoid possible ambiguity.

The managers knew that risks are potentially interdependent, but did not have the tools and metrics to study the influence of interdependencies on the global behavior of the project. It means that this complimentary information was immediately judged as useful, since it permitted to:

- confirm several intuitions (the manager thinks that this risk may be considered with a higher priority level than its direct criticality assessment);

- provide some new findings, e.g., about risks with a significant difference between classical and non-classical indicators and rankings.

The reliability of probability estimates in the context of projects is rarely good enough, because of the unicity of projects in terms of at least one of its dimensions (objectives, context, resources, geographical location, etc.) This lack of similar experience does not permit to propose a statistically sound estimation of a probability (or an estimation model). The 
principle is then to transform these numerical inputs into numerical outputs, where gaps and orders of magnitude are analyzed, not precise values. Knowing that we have this lack of reliability in estimates, or error margin, we suppose that gaps between outputs should be high enough to be significant. The ranking swaps for instance are interesting to analyze, particularly if they involve putting a low-level risk at a high position in importance measure-based rankings, like R10 for instance. On the opposite, R2 and R37 are always very close to each other, and the fact that in one ranking R2 is behind R37 (or not) may not mean that one should be prioritized. It is only when differences are significant, like R43 which was initially the most critical risk, and which appears only one time in the new rankings of $R A I, R R I$ and $M R I$ respectively.

The existence of differing rankings according to various indices is not a conflict, since it gives different information and different reasons for proposing a tailored response action for each risk. For instance, a critical risk with less influence on the network can be treated with classical mitigation or avoidance of its direct consequences. A risk with a low criticality but a high importance on the network may be treated with a preventive action to cut propagation chain at the source. This means that the budget invested to prevent this source risk may be cancelled for other risks which are downstream in the reaction chain and initially considered as more critical. We argue that it is usually preferable to act on upstream events of a chain rather than on downstream events, since the latter generally have higher amounts at stake and more expensive treatment actions.

\section{CONCLUSIONSAND PERSPECTIVE}

This paper presents an original method for project risk analysis and prioritization using importance measures. Risk interactions are accounted for with the purpose of modeling the complexity of interdependent project risks. It is an initial step to develop dependency-driven risk assessment methods. We have showed how the proposed approach can be applied to a real case study of a large engineering project and illustrated that it serves as a powerful complement to the classical project risk analysis.

Various importance measures have been proposed with different purposes for risk analysis and prioritization. For example, the Marginal Risk Importance (MRI) indicates the potential influence range of a risk on the global risk exposure; the Risk Achievement Importance (RAI) provides information to identify the risks which may be dangerous if occurs, even if they are estimated at a low level of exposure; Risk Reduction Importance $(R R I)$ helps to identify the risks which are the most effective targets for planning mitigation actions. The classical criticality analysis of risks can only evaluate the risks that affect the global project performance in a local point of view without taking into account risk interactions. Using the importance measures permits to identify the key factors (i.e., either spontaneous reasons or particular risk interactions) in the risk network that most affect the global performance in terms of risk exposure. For supporting subsequent decisions with respect to risk response planning, this approach enables manager to combine classical risk mitigation strategies (avoidance, mitigation, transfer and acceptance) with new ones which help facing the complexity of risk network: protecting risks due to their position in the network, changing the actors who own risks and/or the organization to adapt it to the current complexity, and reducing the complexity by acting for instance on important risk interactions instead of risks only.

The current study still has a number of limitations. For example, it only considers impact of dependencies on risk materialization; however, the related changes in probability of occurrence and severity of consequenceswill be included. Besides, the risk impacts/consequences are in essence multi-dimensional, namely in terms of schedule, cost, quality, etc., and thus with difficulties to create comparable scales. This approach employs a DSM-based method with pair-wise comparisons to model risk interactions. However, it may fail in accounting for some types of dependencies, for example, a risk may materialize (or change its properties) only as a function of two other risks occurring[47]. This kind of scenarios should be noticed and future work will be proposed to model them.

Moreover, risk clustering and importance measures of the risk groups will be studied, in order totake into account the synergy or co-effects of risks with respect to mitigation actions planning.Some probabilistic-based risk methods like Monte Carlo analysis will also be considered and compared. Finally, in current study, we assume that the risk network structure do not change during the project development. As perspective, the dynamic situations would be involved in the model.

\section{APPENDIX}

\section{Nomenclature}

\begin{tabular}{|c|c|}
\hline$R_{i}$ & risk $i$ \\
\hline$R R_{i j}$ & $(i, j)$-th element in the risk interaction matrix \\
\hline$P_{i}$ & probability measure of risk $i$ \\
\hline$I_{i}$ & impact measure of risk $i$ \\
\hline$T P_{i j}$ & transition probability between risk $j$ and risk $i$ \\
\hline Criticality $_{i}$ & criticality measure of risk $i$ \\
\hline$O$ & global risk exposure \\
\hline$P^{\prime}$ & simulated risk probability \\
\hline $\operatorname{sim}$ & mulated output of global risk exposure \\
\hline$O($ base $)$ & $\begin{array}{l}\text { estimated value of } O \text { without carrying out risk } \\
\text { management activities }\end{array}$ \\
\hline$O^{\prime}\left(R_{i}=1\right)$ & $\begin{array}{l}\text { the value of } O \text { given that the spontaneousprobability } \\
\text { of Risk } i \text { is set to } 1 \text { while the other risks remain the } \\
\text { original status }\end{array}$ \\
\hline$O^{\prime}\left(R_{i}=0\right)$ & $\begin{array}{l}\text { the value of } O \text { given that the spontaneous } \\
\text { probabilityof Risk } i \text { is set to } 0 \text { while the other risks } \\
\text { remain the original status }\end{array}$ \\
\hline$O^{\prime}\left(e_{i \rightarrow j}=1\right)$ & $\begin{array}{l}\text { the value of } O \text { given that the transition probability of } \\
\text { risk interaction from } R_{i} \text { to } R_{j} \text { is set to } 1 \text { (the others } \\
\text { remain) }\end{array}$ \\
\hline$O^{\prime}\left(e_{i \rightarrow j}=0\right)$ & $\begin{array}{l}\text { the value of } O \text { given that the transition probability of } \\
\text { risk interaction from } R_{i} \text { to } R_{j} \text { is set to } O \text { (the others } \\
\text { remain) }\end{array}$ \\
\hline$R A V$ & risk achievement value \\
\hline$R R V$ & risk reduction value \\
\hline$M R V$ & marginal risk value \\
\hline$R A I$ & risk achievement importance \\
\hline$R R I$ & risk reduction importance \\
\hline$M R I$ & marginal risk importance \\
\hline
\end{tabular}


$R A I^{I} \quad$ risk interaction achievement importance

$R R I^{I} \quad$ risk interaction reduction importance

$M R I^{I} \quad$ marginal risk interaction importance 
TABLE III

CLASSICAL PROJECT RISK LIST OF THE TRAMWAY PROJECT

\begin{tabular}{|c|c|c|c|c|c|}
\hline $\begin{array}{l}\text { Risk } \\
\text { ID }\end{array}$ & Risk Name & Risk Domain & $\begin{array}{c}\text { Evaluated Risk } \\
\text { Probability Scale }\end{array}$ & $\begin{array}{l}\text { Evaluated Risk } \\
\text { Impact Scale }\end{array}$ & $\mathbf{P} * \mathbf{I}$ \\
\hline 1 & Safety studies & Technical & 1 & 1 & 1 \\
\hline 2 & $\begin{array}{l}\text { Liquidated damages on intermediate milestone and } \\
\text { delay of Progress Payment Threshold }\end{array}$ & Contractual & 7 & 8 & 56 \\
\hline 3 & Vehicle storage in another city & Contractual & 9 & 5 & 45 \\
\hline 4 & Vandalism on site & Contractual & 1 & 3 & 3 \\
\hline 5 & $\begin{array}{l}\text { Traction/braking function : behavior in degraded } \\
\text { mode on slope }\end{array}$ & Technical & 3 & 2 & 6 \\
\hline 6 & New local laws and regulations & Contractual & 1 & 3 & 3 \\
\hline 7 & Traffic signaling, priority at intersections & Contractual & 6 & 5 & 30 \\
\hline 8 & $\begin{array}{l}\text { Unclear Interface with the Client, for Infrastructure } \\
\text { equipment }\end{array}$ & Contractual & 1 & 2 & 2 \\
\hline 9 & Delays due to client late decisions & Contractual & 9 & 1 & 9 \\
\hline 10 & Travel Time performance & Technical & 1 & 3 & 3 \\
\hline 11 & Limited Force majeure definition & Contractual & 1 & 4 & 4 \\
\hline 12 & Operating certificate delay & Contractual & 9 & 4 & 36 \\
\hline 13 & Reliability \& availability targets & Technical & 3 & 3 & 9 \\
\hline 14 & Permits \& authorizations & Contractual & 9 & 2 & 18 \\
\hline 15 & Insurance deductibles & Financial & 1 & 3 & 3 \\
\hline 16 & Archeological findings & Contractual & 9 & 3 & 27 \\
\hline 17 & Discrepancies Client / Operator / Concessionaire & Contractual & 3 & 5 & 15 \\
\hline 18 & Civil Work delay \& continuity & Contractual & 9 & 4 & 36 \\
\hline 19 & Responsibility of client on Civil Work delay & Contractual & 9 & 2 & 18 \\
\hline 20 & On board CCTV scope & Technical & 5 & 1 & 5 \\
\hline 21 & Noise \& vibration attenuation & Technical & 3 & 6 & 18 \\
\hline 22 & $\begin{array}{l}\text { Potential risks of claim from Civil Work } \\
\text { subcontractor }\end{array}$ & Contractual & 5 & 5 & 25 \\
\hline 23 & Harmonics level & Technical & 1 & 2 & 2 \\
\hline 24 & Non compliance contractual Rolling Stock & Technical & 1 & 6 & 6 \\
\hline 25 & $\begin{array}{l}\text { Non compliance technical specifications Rolling } \\
\text { Stock }\end{array}$ & Contractual & 3 & 4 & 12 \\
\hline 26 & Exchange risk on suppliers & Financial & 1 & 3 & 3 \\
\hline 27 & Track installation machine performance & Client/Partner/Subcontractor & 3 & 2 & 6 \\
\hline 28 & Tax risk on onshore & Financial & 1 & 2 & 2 \\
\hline 29 & Additional poles overcost for Tramway Company & Contractual & 9 & 4 & 36 \\
\hline 30 & Overcost due to Security requirements for trains & Technical & 5 & 4 & 20 \\
\hline 31 & Track insulation & Technical & 1 & 1 & 1 \\
\hline 32 & Delay for energizing & $\begin{array}{l}\text { Project management, } \\
\text { Construction site }\end{array}$ & 3 & 2 & 6 \\
\hline 33 & Fare collection requirements & Contractual & 5 & 3 & 15 \\
\hline 34 & Construction safety interfaces & Technical & 1 & 1 & 1 \\
\hline 35 & Electromagnetic interferences & Technical & 1 & 2 & 2 \\
\hline 36 & Exchange risk & Financial & 1 & 2 & 2 \\
\hline 37 & $\begin{array}{l}\text { Risk of partial rejection of our request for EOT } \\
\text { (Extension Of Time) }\end{array}$ & Contractual & 9 & 7 & 63 \\
\hline 38 & Interface rail / wheel & Technical & 3 & 2 & 6 \\
\hline 39 & Risk on Certification of our equipment & Country & 1 & 2 & 2 \\
\hline 40 & OCS installation & $\begin{array}{l}\text { Project management, } \\
\text { Construction site }\end{array}$ & 7 & 5 & 35 \\
\hline 41 & Banks stop financing the project & Contractual & 7 & 3 & 21 \\
\hline 42 & $\begin{array}{l}\text { Costs of modifications not covered by EOT } \\
\text { agreement }\end{array}$ & Contractual & 1 & 4 & 4 \\
\hline 43 & Return profit decrease & Financial & 9 & 8 & 72 \\
\hline 44 & Extra trains & Contractual & 1 & 6 & 6 \\
\hline 45 & Pedestrian zones & Technical & 1 & 2 & 2 \\
\hline 46 & Train performance & Technical & 3 & 2 & 6 \\
\hline 47 & Waiting time at stations & Contractual & 5 & 1 & 5 \\
\hline 48 & Depot delay & Technical & 9 & 2 & 18 \\
\hline 49 & Error in the Survey (topography) & Technical & 1 & 1 & 1 \\
\hline 50 & Ticketing design delays & Contractual & 7 & 1 & 7 \\
\hline 51 & Track installation delay & Technical & 7 & 2 & 14 \\
\hline 52 & Reengineering / Redesign & Technical & 9 & 2 & 18 \\
\hline 53 & Slabs pouring delay & Technical & 5 & 1 & 5 \\
\hline 54 & Initial specifications of CW (Civil Work) & Technical & 5 & 1 & 5 \\
\hline 55 & Available cash flow decrease & Financial & 9 & 7 & 63 \\
\hline 56 & Rolling stock delivery delay & Technical & 3 & 1 & 3 \\
\hline
\end{tabular}




\section{REFERENCES}

[1] PMI, "A Guide to the Project Management Body of Knowledge (PMBOK) (2008 ed.)," ed. Newton Square, PA, USA: Project Management Institute, 2008.

[2] T. Raz and E. Michael, "Use and benefits of tools for project risk management," International Journal of Project Management, vol. 19, pp. 9-17, 2001

[3] T. Williams, "A classified bibliography of recent research relating to project risk management," European Journal of Operational Research, vol. 85, pp. 18-38, 1995.

[4] D. Baccarini and R. Archer, "The risk ranking of projects: a methodology," International Journal of Project Management, vol. 19, pp. 139-145, 2001.

[5] A. Ahmed, et al., "A review of techniques for risk management in projects," Benchmarking: An International Journal, vol. 14, pp. 22-36, 2007.

[6] A. T. Cox Jr, "What's wrong with risk matrices?," Risk Analysis, vol. 28, pp. 497-512, 2008.

[7] D. W. Hubbard, The failure of risk management: why it's broken and how to fix it. New jersey: John Wiley \& Sons Inc, 2009.

[8] C. Chapman and S. Ward, "How to manage project opportunity and risk: why uncertainty management can be a much better approach than risk management," ed. Chichester, Sussex: John Wiley \& Sons Ltd., 2011.

[9] A. Salado, et al., "Taxonomy and Categorization of Uncertainties in Space Systems with an Application to the Measurement of the Value of Adaptability," in AIAA Space Conference 2012, Pasadena, USA, 2012.

[10] A. Salado and R. Nilchiani, "Assessing the Impacts of Uncertainty Propagation to System Requirements by Evaluating Requirement Connectivity," in INCOSE International Symposium, Philadelphia, USA, 2013, pp. 647-661.

[11] D. Baccarini, "The concept of project complexity - a review," International Journal of Project Management, vol. 14, pp. 201-204, 1996.

[12] D. Chu, et al., "Theories of complexity - Common denominators of complex systems," Complexity, vol. 8, pp. 19-30, 2003.

[13] B. Lazzerini and L. Mkrtchyan, "Analyzing risk impact factors using extended fuzzy cognitive maps," IEEE Systems Journal, vol. 5, pp. 288-297, 2011.

[14] D. D. Wu, et al., "A risk analysis model in concurrent engineering product development," Risk Analysis, vol. 30, pp. 1440-1453, 2010.

[15] S. V. Buldyrev, et al., "Catastrophic cascade of failures in interdependent networks," Nature, vol. 464, pp. 1025-1028, 2010.

[16] J. Sanz, et al., "Dynamics of interacting diseases," Physical Review X, vol. 4, p. 041005, 2014.

[17] C.-Y. Xia, et al., "Effects of delayed recovery and nonuniform transmission on the spreading of diseases in complex networks," Physica A: Statistical Mechanics and its Applications, vol. 392, pp. 1577-1585, 2013.

[18] Y.-Y. Liu, et al., "Controllability of complex networks," Nature, vol. 473, pp. 167-173, 2011.

[19] S. Boccaletti, et al., "Complex networks: Structure and dynamics," Physics reports, vol. 424, pp. 175-308, 2006.

[20] C. Fang and F. Marle, "A simulation-based risk network model for decision support in project risk management," Decision Support Systems, vol. 52, pp. 635-644, 2012.

[21] C. Eckert, et al., "Change and customisation in complex engineering domains," Research in Engineering Design, vol. 15, pp. 1-21, 2004.

[22] B. Kloss-Grote and M. A. Moss, "How to measure the effectiveness of risk management in engineering design projects? Presentation of RMPASS: a new method for assessing risk management performance and the impact of knowledge management-including a few results," Research in Engineering Design, vol. 19, pp. 71-100, 2008.

[23] L. W. Birnbaum, "On the importance of different elements in a multi-element system. ," Multivariate analysis, vol. 2. Academic Press, New York, 1969.

[24] W. Kuo and X. Zhu, Importance Measures in Reliability, Risk, and Optimization: Principles and Applications: Wiley, 2012.

[25] X. Zhu and W. Kuo, "Importance measures in reliability and mathematical programming," Annals of Operations Research, pp. DOI: 10.1007/s10479-012-1127-0, 2012.

[26] M. Xie, "On some importance measures of system components," Stochastic processes and their applications, vol. 25, pp. 273-280, 1987.
[27] M. Xie and B. Bergman, "On a general measure of component importance," Journal of statistical planning and inference, vol. 29, pp. 211-220, 1992.

[28] M. C. Cheok, et al., "Use of importance measures in risk-informed regulatory applications," Reliability Engineering \& System Safety, vol. 60, pp. 213-226, 1998.

[29] M. Van der Borst and H. Schoonakker, "An overview of PSA importance measures," Reliability Engineering \& System Safety, vol. 72, pp. 241-245, 2001.

[30] J. K. Vaurio, "Importance measures in risk-informed decision making: Ranking, optimisation and configuration control," Reliability Engineering \& System Safety, vol. 96, pp. 1426-1436, 2011.

[31] E. Borgonovo, "Differential importance and comparative statics: An application to inventory management," International Journal of Production Economics, vol. 111, pp. 170-179, 2008.

[32] E. Zio, et al., "Importance measures-based prioritization for improving the performance of multi-state systems: application to the railway industry," Reliability Engineering \& System Safety, vol. 92, pp. 1303-1314, 2007.

[33] T.-M. Choi, et al., "Mean-variance analysis for the newsvendor problem," Systems, Man and Cybernetics, Part A: Systems and Humans, IEEE Transactions on, vol. 38, pp. 1169-1180, 2008.

[34] J. Li, et al., "Mean variance analysis of fast fashion supply chains with returns policy," Systems, Man, and Cybernetics: Systems, IEEE Transactions on, vol. 44, pp. 422-434, 2014.

[35] Y. Zhao, et al., "Mean-risk analysis of wholesale price contracts with stochastic price-dependent demand," Annals of Operations Research, pp. $1-28,2014$.

[36] D. Vose, Risk Analysis: a Quantitative Guide: John Wiley \& Sons Inc, 2008.

[37] E. Kujawski, "Analysis and critique of the system readiness level," Systems, Man, and Cybernetics: Systems, IEEE Transactions on, vol. 43, pp. 979-987, 2013.

[38] J. L. Fleiss, Statistical methods for rates and proportions. New York: John Wiley\&Sons, 1981.

[39] C. Chapman and S. Ward, Project Risk Management - Processes, Techniques and Insights. Chichester: John Wiley \& Sons, 2003.

[40] D. Hillson, et al., "Managing project risks using a cross risk breakdown matrix," Risk Management, pp. 61-76, 2006.

[41] C. Rafele, et al., "Understanding project risk exposure using the two-dimensional risk breakdown matrix," in Proceeding of 2005 Project Management Institution Global Congress, Edinburgh, Scotland, 2005.

[42] F. Marle and L. Vidal, "Potential Applications of DSM Principles in Project Risk Management," in 10th International Design Structure Matrix Conference, DSM'08, Stockholm, Sweden, 2008, pp. 157-168.

[43] D. Steward, "The Design Structure Matrix: a method for managing the design of complex systems," IEEE Transactions on Engineering Management, vol. 28, pp. 71-74, 1981.

[44] T. Browning, "Applying the design structure matrix to system decomposition and integration problems: a review and new directions," IEEE Transactions on Engineering Management, vol. 48, pp. 292-306, 2001.

[45] T. Saaty, The Analytic Hierarchy Process: Planning, Priority Setting, Resource Allocation: McGraw-Hill, 1980

[46] L. Vidal, et al., "Developing an original framework to assess project complexity thanks to the use of the AHP," in International Conference on Engineering Design ICED'09, Stanford, USA, 2009.

[47] A. Salado and R. Nilchiani, "The concept of order of conflict in requirements engineering," IEEE Systems Journal, In Press, 2014.

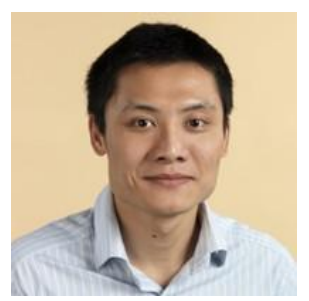

Chao FANG received the B.S. and M.S. degrees from Xi'an Jiaotong University, P.R. China, and the Ph.D. in Industrial Engineering from Ecole Centrale Paris, France in 2011. He is currently associate professor at Economics and Management School, Wuhan University, P.R. China. His research interests include project management, risk management, complex system modeling and simulation. 


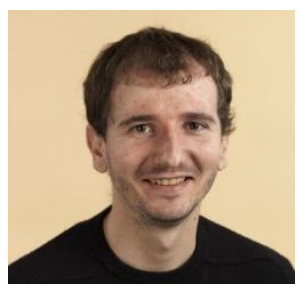

Franck MARLE received his MSc degree at Ecole Centrale Lyon (1997) and the Ph.D. at Ecole Centrale Paris in 2002. He is professor in project management at Ecole Centrale Paris. He is also Director of the TOTAL Chair "Managing Procurement Risks in Complex Projects" since April 2013. He is now conducting research works about risk modeling in projects, interactions modeling and assessment, and decision-making in project and multi-projects context.

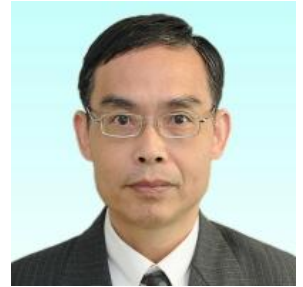

Min Xie (F'06)received the Ph.D. degree in Quality Technology from Linkoping University, Sweden, in 1987. He is currently Chair Professor at Department of Systems Engineering and Engineering Management, City University of Hong Kong. His research focuses on statistical quality and reliability engineering, and has published more than 200 journal articles and eight books. 